\title{
Leitura antropológica sobre Angolanidade
}

Patrício Batsîkama | UFP'

\section{Introdução.}

A teorização de "angolanidade" deveu-se, em grande parte, da corrente freyriana sobre luso-tropicalismo. Faremos a nossa releitura sobre esse assunto antes de falar propriamente sobre "angolanidade", para depois abordar separadamente as quatro angolanidades que a Historia terá registado, nomeadamente: (i) angolanidade apriorística; (ii) angolanidade rizomática; (iii) angolanitude; (iv) angolanidade aposterioristica.

\section{Luso-tropicalismo em Angola.}

As ideias de Gilberto Freyre alastram o império luso nos "tristes tropiques". No Brasil onde nasce a teorização, nota-se: (i) a bicontinentalidade do português, o colono, aquele que dita regras e estabelece o jogo societário; (ii) a bicontinentalidade do africano, o colonizado, aquele que além de cumprir com as regras pode associar-se ${ }^{2}$ ao colono e a sua descendência partilhar as terras; (iii) a unicontinentalidade do ameríndio, o colonizado, aquele a quem pertence verdadeiramente a terra e que, por medidas repressivas, é obrigado a ceder/perder parcialmente por regra ou por relações que resultam com o resto dos constituintes societários (africanos e portugueses).

Pela lógica dos seus protagonistas, o português/colonizador parece representar o EU: ele dita e estabelece o jogo social. Africano assumiria aqui as funções representativas de Não-Eu por servir-se de "aliado" trazido pelo EU num espaço primordialmente pertencendo ao OUTRO, que é o ameríndio. Essa será a estrutura que, ao longo da nossa reflexão partindo dos dados empíricos, se verificará como fio operacional das representações não só na luso-tropicalidade ou luso-tropicalismo na obra de Gilberto Freyre ("Casa Grande e Senzala" e "O mundo que o português criou”, principalmente), mas, também, na construção da angolanidade.

\section{Expansão do luso-tropicalismo.}

${ }^{1}$ Universidade Fernando Pessoa, Porto. Este texto é um resumo parcial do nosso trabalho de tese de doutoramento, orientado pelo prof. Dr. Álvaro Campelo.

${ }^{2}$ Há uma leitura generalizada segundo a qual a união do colono com a mulher colonizada não foi pacífica. Ela terá sido violentada/forçada, a mulher colonizada/escravizada, a associar-se (sexualmente) com o colonizador. Justifica-se geralmente, que raros são os casos em que a mulher colonizadora associa-se com homem colonizado. 
A ideia interessa inúmeros intelectuais no Brasil: Jorge Amado, José Lins do Rego, Raquel de Queirós, entre outros. Freyre chega na Ásia e na África, precisamente em Angola, onde inicialmente prefere legitimar a sua teoria em meras convicções (Angola não teria necessidade de ser independente de Portugal). Mais tarde (1951-1959), admitiria a possibilidade duma Angola independente.

\section{Representações de "EU”, "Não-EU” e "OUTRO".}

Partindo de cinco textos fundamentais em antropologia (Allier, 1927; Geertz, 1972/1973; Malinowski, 1926/1944; Levis-Strauss, 1962/1977), podemos descrever as representações (ou os a priori ontológicos3) do luso-tropicalismo da seguinte maneira (Auge; Colleyn, 2004: 15)4:

(a) EU: o Português apresenta quase todos propósitos do "EU”, isto é, do executor. Aliás, o luso-tropicalismo ou "mundo que criou" o modelo que ele cria imprime a sua "identidade/personalidade" inicial como norma. Ipso facto o resto das propostas que intervêm nessa "hiper-identidade vestem os traços personalísticos do EU, nomeadamente: (i) línguas do colonizador que se torna língua unificadora; (ii) hábitos diluídos pelo espaço e o processo de adaptação de ambas partes 6 ainda teleguiam o comportamento psicossocial.

(b) "Não-EU”. A implantação do português no Brasil foi acompanhada com um "não-português", o Africano/negro. No "aglomerado brasileiro", lusotropicalismo apresenta os traços do "Não-Eu": (i) na língua o português se instala já com neologismos no Brasil; (ii) hábitos não só são misturados, mas sim desenvolvem-se em paralelo na fase inicial e média.

(c) "OUTRO": os constituintes são: (i) cosmovisão não-lusitana na língua portuguesa: a pronúncia que modifica a musicalidade de Luís de Camões, será seguida de uma tipificação; (ii) contrastes psicossociológicos são influenciados pela interiorização/exteriorização quer linguagética quer comportamental. Por conseguinte, influenciam-na a sua vez, e de modo variável e dinâmico.

A seguir, iremos abordar da obra de Gilberto Freyre comparando as representações de "Eu”, "Não-Eu” e "Outro" na realidade angolana.

\section{Luso-tropicalismo em Angola.}

Na academia angolana, Mário António Fernandes de Oliveira - discípulo de Gilberto Freyre (1900-1987) - foi o fundador da corrente da crioulidade (mulatidade) em Angola.

\footnotetext{
3 Bordieu chama agentes. São para nós os "a priori” ontológicos por que: (i) constituem inseparavelmente um agente singular; (ii) representam - enquanto todos - identidade singular.

4 "O antropólogo encontra aí as regularidades e, comparando aos outros, pode teorizar estas diferentes elaborações de sentido".

5 A língua sendo expressão, ela obedece a uma estrutura pensativa que explica toda uma cultura, história dum povo (filologia) e, até certo ponto,

${ }^{6} \mathrm{O}$ que se assiste aqui é as dificuldades das "lusíadas" tropicalizar-se.
} 
Contudo, importa salientar que o nacionalista angolano Mário Pinto de Andrade reagiu explosivamente aos textos de Gilberto Freyre, logo depois as suas conferências nas universidades americanas (em 1954).

Tentamos reconstruir as representações sociais, neste caso. EU/luso-descendente angolano; Outro/afro-angolano. Reparamos que o EU e Não-EU/Eu(-1) são contrários: EU \# EU(-1). Isso implicaria que se EU for a língua portuguesa, Não-EU seria língua angolana patrimonial (língua nacional). De modo igual, importa reconsiderarmos OUTRO como afroangolano pela obra portuguesa ( $O$ mundo que o Português criou) que implica a fraternidade entre Angolano e outras colónias africanas. Cada um trouxe um pouco da sua cultura originária. Nesse caso, numa primeira linha teremos:

(i) EU: português/luso-descendente

(ii) Não-EU: autóctone angolano 7

(iii) Outro: afro-angolano.

Comparando ao quadro que anteriormente estabelecemos na obra de Gilberto Freyre, há - ao que nos parece - uma incongruência:

\section{Gilerto Freyre}

(1) EU/Português

(2) Não-EU: Africano/luso-companheiro angolano

(3) OUTRO: Ameríndio

\section{Angolanidade}

(1) EU: Luso-descendente

(2) Não-EU: Autóctone

A diferença epistemológica na estruturação das representações dum mesmo conceito ou teoria/método na linguagem de Mário Pinto de Andrade - reverteria, talvez no fundo identitário das culturas que acolhem, plataformas discrepantes: brasileira e angolana. Brasil que acolhe o EU, não o faz isoladamente. Este EU está acompanhado de outro EU que não é EU, isto é EU(-1) ou ainda Não-EU. O EU chama-se português, e o Não-EU é africano. Nessa lógica, o OUTRO que lhes acolhe é Ameríndio. O caso parece diferente para África, e Angola em particular. O EU continua a ser o português, mas ao instalar sua cultura em Angola, ele o faz quase exclusivamente ${ }^{8}$. É verdade que, em Angola, encontremos línguas cuja origem é Macau ou Cabo Verde..., mas no tecido cultural angolano - veiculado na literatura (Lopes de Sá, S/d: 1) ou não - estes ingredientes culturais quase não são presentes, e se possível encontrá-los, de forma mascarados e com aparências da realidade endógena. Também, o africano no Brasil é

\footnotetext{
7 "Autóctone" é aqui uma categoria formal. Historicamente, Angola pertenceria aos !Kung (Batsîkama: 2011). Estes foram invadidos pelos proto-Njila (Vansina, 2004) e pelos Bantu. De 1491 ate 1917 houve a territorialização portuguesa em Angola.

8 Os contratados que Portugal trouxe em Angola eram oriundo de: (i) São-tome; (ii) Brasil; (iii) Índias.
} 
escravizado e depois fraternizado através da religião. Em Angola é o contrário: o angolano resiste a instalação portuguesa, por um lado e por outro, não aceita qualquer esclavagismo no seu território (embora se verifique a escravidão passiva, sustentada nos usos e costumes internos).

A outra discrepância seria as representações de OUTRO. Enquanto no Brasil o OUTRO é o autóctone, em Angola, ele é "Afro-angolano": o OUTRO ameríndio foi quase recuado nas "terras do fim do mundo", ele que é autóctone. Ao contrário, o OUTRO angolano que não é autóctone parece ter, ainda, espaço na integração social, por causa da língua portuguesa (língua das centralidades e quase desconhecida no "interior"). Não só partilha o mesmo "género estrutural" de autóctone que o "Eu”, mas é literalmente apadrinhado por este. É por isso que na visão sociológica, a destribalização era tida como uma autêntica destruição das culturas internas através das políticas violentas de assimilação. Mário Pinto de Andrade a considera uma brutalização selvática e não civilizadora como o defendera a teoria freyreana.

\section{Angolanidade apriorística.}

Dois condicionantes permitem que seja o MPLA a começar com teorias a volta disso: (i) os membros do MPLA/luta intelectual integravam associações dos literários - nos anos 40-70 do século XX - nos circuitos internacionais da africanidade, negritude, etc.; (ii) os primeiros a utilizar o termo pertenciam a MPLA (Andrade, 1962b) e os primeiros teóricos surgiram no MPLA: Mário Pinto de Andrade (Kajibanga, 2000) e Viriato da Cruz.

Mário Pinto Andrade é da opinião que:

“... a angolanidade requer enraizamento cultural e totalizante das comunidades humanas, abraça e ultrapassa dialecticamente os particularíssimos das regiões e das etnias, em direcção à nação. Ela opõe-se a todas as variantes de oportunismo (com as suas evidentes implicações políticas) que procuram estabelecer uma correspondência automática entre a dose de melanina e dita autenticidade angolana. Ela é, pelo contrário, linguagem da historicidade dum povo". 9

O que significaria angolanidade apriorística? Os militantes do MPLA observam a inoperacionalidade do luso-tropicalismo e tomam medidas correctivas a partir de duas constatações: (i) as "etnias" rumo à nação angolana incorporavam num discurso hegemónico da crioulidade bio-cultural e da sua abertura ao mundo; (ii) construção do sujeito colectivo (Spinoza, 2010: 23-25) angolano implicava o diálogo civilizacional do "Eu" e "Outro" em duas

9 Conferir Victor Kajibanga (Kajibanga, 2004: 130-131) 
dimensões: histórica e sociológica. ${ }^{10}$ Isto é, nessa primeira observação, angolanidade parte das potenciais socioculturais e humanas que compõem Angola: isto é, um "a priori" histórico/sociológico contextual. Em 1959, a ideia é lançada/Costa Andrade; em 1960 Mário Pinto de Andrade constrói conceitos; em 1961 Agostinho Neto vê certo construtivismo cultural adequado para um país plural em termo de raça e povo. São pessoas cultas, viajadas e inteligentes que utilizam o termo. Teoriza-se, assim, o discurso nacionalizador dos "grupos societários": angolano, afro-angolano, luso-descendente, euro-angolano. A ideia predominante aqui é construir uma nação a partir dos traços culturais de todas forças sociais angolanas ${ }^{11}$, e como no "rise of nationalism", inevitável aos conflitos étnicos internos emergentes (Geertz, 1988).

Interessa-nos agora perceber essa angolanidade apriorística no comportamento angolano. A nossa leitura é simples: sendo uma reflexão crítica, mas sequencial do lusotropicalismo, angolanidade apriorística estratificou os traços culturais do nacional na mesma ordem de "Eu”, "Não-Eu” e "Outro" luso-tropicalistas.

Consideramos o MPLA/local onde Ambundu/luso-descendente assumem o "Eu”. Quem será o "Não-Eu” e quem poderá ser o "Outro"? Fazendo a pergunta de outra forma, como funcionariam as relações epistemológicas (Bordieu, 1964: 32-34) entre os traços culturais constituintes da "Cultura nacional" entre os diferentes "actores identitários" nessa angolanidade?

Vamos parametrizar as nossas análises num período de 1975-2008 por duas razões: (i) a composição dos dirigentes do MPLA nas propostas dos Acordos de Alvor em 1975; (ii) a composição dos dirigentes do MPLA depois das eleições gerais de 1992 e de 2008. Desse quadro, podemos tirar algumas conclusões que nos façam compreender quem seria o "Eu" (grupo social hegemónico), quem seria o "Não-Eu" (grupo social dominado) e quem poderia ser o "Outro" (grupo social dialógico do "Eu"). Dai, compreenderemos o jogo simbólico do poder (Bordieu, 1989).

$\mathrm{Na}$ angolanidade apriorística construída pelo MPLA podemos encontrar as seguintes características dos constituintes:

(a) "Eu": assimilado do litoral; luso-descendente;

(b) "Não-Eu": não-assimilado do interior; angolanos autóctones"12;

(c) "Outro": afro-angolano do litoral; português/antigo colono ${ }^{13}$.

\footnotetext{
10 Partimos da teoria de Pierre Bordieu (Bordieu, 1991:113-119). Para compreender a nossa estruturação dos "constituintes" da Angolanidade: (Bordieu, 1992; Bordieu, 1996).

${ }^{11}$ O termo "etnia" é evitado, para enaltecer a "nação".

${ }_{12}$ Partimos do pressuposto que os afro-angolanos viviam mais no litoral e nas centralidades urbanísticas onde tinham, de facto, espaço. No interior, o seu estatuto levava-os na categoria de um "sub-angolano", por não ter linhagem local. São autóctones por ser oriundos só de Angola.

${ }_{13}^{13}$ Principalmente aqueles que constam na lista dos indicados para constituir o Governo, nos Acordos de Alvor.
} 


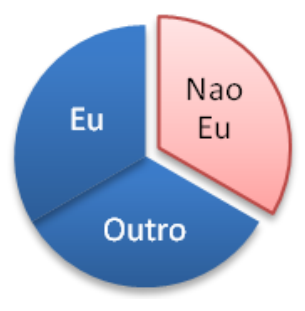

Importa salientar que tentaremos considerar essa estrutura ("Eu", "Não-Eu", "Outro") como suporte de cultura, e também como texto (Geertz, 1972)14 para lermos as dinâmicas das estruturas sociais angolanas a volta da angolanidade apriorística (e outras também). É importante considerar o local onde essas ideias estão a ser construídas: Europa/Ocidente e África. Isto é, fora e dentro de Angola (Messiant, 2009-2: 123-125). Esse "fora de Angola" pode significar também "longe de Angola", mas nesse caso, o "Litoral angolano" seria mais próximo do que o "Interior angolano". Dai justificar-se-á porque "Eu" teria o "Outro" como seu interlocutor directo.

A crioulidade significava "abertura ao mundo" na sua perspectiva cultural. Razão pela qual angolanidade apriorística, ao construir teoricamente o sujeito colectivo angolano, busca no "Outro" a sua aceitação continental (África) e universal (Portugal/Brasil). É na base disso (Bordieu. 1964: 56) que MPLA se construiu e constrói as suas linhas políticas, desde o governo dos Acordos de Alvor até 2008. ${ }^{15}$ De forma resumida, eis o quadro que se apresenta:

(i) 50,29\%: assimilados litorais;

(ii) $\quad 22,40 \%$ : luso-descendentes ${ }^{16}$;

(iii) 15\%: afro-angolanos;

(iv) 13\%: não assimilados do Interior.

Embora exista uma categorização semelhante a Cristine Messiant (2009-2: 206-209) e mesmo que corresponda a distribuição socioeconómica angolana pós-independência (Guerra, 1979), importa salientar que a nossa resulta das nossas recolhas e análises. Provisoriamente constatamos que cerca de $72,69 \%$ são Litorais e luso-descendentes, com poder financeiro/económico. Quer com isso dizer, o "Eu” representa nessa angolanidade apriorística, o Litoral e o luso-descendente. O "Não-Eu" é oriundo de Interior: Côkwe, Kôngo, Umbûndu... e mesmo Ambûndu não assimilados (Eriksen, 1993: 22-23), e busca sua estabilidade financeira nos "mercados alternativos", a ponto de indirectamente cumprir as estratégias estabelecidas pelo "Eu". Por conseguinte, sofre dupla crise de identidade: busca (hipocritamente) na cultura

${ }^{14}$ No seu artigo: "Deep Play: Notes on the Balinese Cockfight", ele escrevia: "The cockfight's function, if you want call it that, is interpretative; it is a Balinese reading of Balinese experience; a story they tell themselves about themselves".

15 Consideramos: (i) a lista do governo dos Acordos de Alvor; (ii) os integrantes do Governo de Agostinho Neto; (iii) os dos Governos de José Eduardo dos Santos; (iv) resultados das eleições de 1992; (v) GURN; (vi) resultados das eleições de 2008.

16 “... A Casa dos Estudantes do Império era muito grande, e a sua vocação não era necessariamente africana... Havia, também, filhos de Colonos, etc. que não estavam particularmente interessados a se descobrir uma negritude, a descobrir-se realmente africana" (Messiant, 2009-2:116). 
litoral/luso-descendente (portuguesa cristã) modelo da sua abertura e prefere afastar-se dos "seus" ${ }^{17}$ Ainda é visível que no litoral se evite falar línguas patrimoniais a fim de ter facilidade às oportunidades. Se por um lado essa postura "Não-Eu" permite-o integrar à estrutura dessa angolanidade apriorística, por outro no conjunto ele é visto em terceira posição na realidade

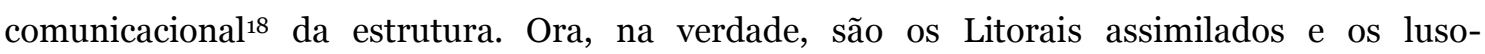
descendentes que estão na forja não só da angolanidade, mas também, na criação do MPLA e do MPLA/Estado. Talvez isso explique a hegemonia (Foucault, 1987) que assumem nessas paragens.

As dissidências internas do MPLA (Mabeko-Tali, 2001) desde as Revoltas Activa e de Leste quer ao 27 de Maio de 1977 (Fragoso; Pedro, 2010) - sem esquecer-se das atrocidades/massacres pós-eleitorais pos-1992 (Eurico, s/d; Roque, 2000) - obedecem a essa estrutura da angolanidade apriorística. Enquanto teoria/conceito, a angolanidade apriorística buscou um instrumento institucional que se chamou Simpósio sobre Cultura Nacional (onde a hegemonia luso-descendente e litoral era expressivamente clara). Esse instrumento institucional discursava já na perspectiva do país (MPLA/partido-Estado).

Culturalmente a hegemonia da angolanidade apriorística (Dias, 1984: 61-62, 76-78) parece declinar a partir de 1992, independentemente do MPLA ter maioria. A brutalização dos "Interior/Não-Eu" através de massacres de 1992 quer em Luanda, quer nas outras províncias (Uige, Huila, por exemplo) vem empobrecer a angolanidade apriorística. Ganha arrogância, barbárie como novos traços operacionais (já não era apenas intelectual/civilizada) e instala uma cultura do medo (Albuquerque, 2002), embora as gerações pós-eleitorais (1992) não parecem conhecer esse medo, embora colateralmente seja visível em alguns casos. ${ }^{19}$

Porém, essa angolanidade ainda está patente, mas de outra forma. Ela sobrevive por duas razões, talvez: (i) as consequências do nacionalismo administrativo e económico tornam neo-capitalista essa angolanidade. A visão hegemónica cultural passa a ser através dos suportes económicos/financeiros. O intercâmbio através da Cultura (língua, música, cinema, dança, etc.) é, sobremaneira, dominado pelo poder financeiro. Ora não só esse poder pertencia ao "Eu" apriorístico (Litorais e Luso-descendentes) que buscou colusão/comunicação com afroangolano, mas, e sobretudo, o "Não-Eu" apriorístico conhecia crise identitária idiossincrática que será agudizada pelo seu medo de perder espaço de sobrevivência (Albequerque, 2004: 32, 39) na estrutura da angolanidade apriorística ${ }^{20}$; (ii) a vulgarização da universidade em Angola ${ }^{21}$, banaliza ipso facto a formação superior. Se os “Não-Eu” que são do Interior virão suas condições

${ }_{17}$ Esse afastamento e hipócrita, mas apenas para garante o clientelismo eleitoral (ainda que as dinâmicas impusessem) ele serve.

${ }^{18} \mathrm{O}$ "Eu" comunica-se sempre com "Outro" e o "Não-Eu/Ele" nem sempre está presente.

19 As manifestações que se tem assistido em Angola/Luânda - desde a Primavera Árabe (2011) - os têm os jovens (entre 17 e 23 anos) como oxigénio.

${ }^{20}$ Importa salientar que o "lugar" que o "Não-Eu” ocupa não é de prestígio, mas humilhante.

${ }_{21}$ Em 2009 o Secretariado de Estado para Ensino Superior (SEES) criou seis universidades públicas nas regiões académicas (que corresponde, na verdade nas regiões económicas que planificou MPLA). 
criadas para formação universitária (abertura ao mundo) a verdade é que tal formação ainda carece de qualidade/excelência. Aqui, angolanidade apriorística (na dimensão já do país) manterá "Eu" (desta vez dinamizado pelas outras angolanidades) no comando (por ter formação qualificada/ser gestor do emprego), e o "Não-Eu" vera a sua revolução estagnada por ainda depender (financeira e economicamente ${ }^{22}$ ) do "Eu" (e "Outro"). Com a ditadura dos banqueiros - na ordem mundial do novo Millenium - a hegemonia cultural/capitalista do "Eu" prevalece, mas desta vez na linha de soft-power.

Dentro da linha da angolanidade/MPLA (apriorística), na sua anatomia social interna ${ }^{23}$, o "Eu" tem poder económico, tecnológico, gere emprego e participa nas estratégias do país senão exclusivamente, pelo menos com alguma arrogância intelectualista. O seu conforto comunicacional continuar a ser possibilitado com "Outro" (Fabian, 1986: 72-74). Ainda é visível hoje em dia no aparelho administrativo que na verdade é a herança da descolonização (Bordieu; Passeron, 1964). Dificilmente o "Não-Eu" assume posições de liderança, mesmo quando busca por outras formas sociais, associar-se com os "Eu". Como "Eu" dialoga normalmente com "Outro", assiste-se (por exemplo) as preferências matrimoniais que ainda obedecem a estrutura da angolanidade apriorística. O "Não-Eu" MPLA beneficia apenas do "entourage" do "Eu" (económica e financeiramente poderoso) e "Outro" (modelo cultural) não desvincula ao risco de ver seu prestígio económico esvanecer (Falola, 2004; Melo, 1994: 37, 43). A crise identitária atinge aqui o nível de humilhação ${ }^{24}$, independentemente dum núcleo multicultural (Frank, 1997: 732) e das pretensões dos constituintes dessa estrutura social (Boas, 1945[1918]). As manifestações emergindo contra o poder estabelecido (Santos, 1994: 111), embora possam ser "reacção natural" dos condicionantes da existência (Khroeber, 1952: 59), criem novas estruturas. Talvez isso justifique o porquê depois da angolanidade [apriorística] ter sido orquestrada como "formula magica" na salvação de Angola (1959/1961), surgirá outra proposta alternativa: angolanidade [rizomática].25 Aqui o local/origem ${ }^{26}$ (Chabal, 2009: 27, 32) desempenha um papel decisivo na estruturação dessas identidades colectivas.

\section{Angolanidade rizomatica/angolanitude.}

O que chamamos angolanidade rizomática é a ideologia sobre a cultura nacional (que define/molda o Angolano nacional) baseando-se nas raízes patrimoniais angolanas. A sobrevalorização interna dessas culturas em relação a cultura europeia (em Angola) faz com que

\footnotetext{
${ }^{22}$ O capitulo I de livro Raisons pratiques (Bordieu) justifica a "luta” entre "Eu”, "Não-Eu” e Outro".

23 Macedo, 1988; Boxer, 1967; Guerra, 1979; Carvalho, 1989: 39-46

${ }^{24} \mathrm{O}$ quadro "Cultura do Interior sendo 'pobre' em relação a Cultura do Litoral sendo rica" convertido no capitalismo de diamante/petróleo permite a autodestruição da Cultura do Interior.

${ }^{25}$ Agostinho Neto foi eleito líder do MPLA para rivalizar o prestigio cultural de Holden Roberto.

${ }^{26}$ Local: a natalidade de um indivíduo é importante, embora em si não outorga directamente o poder de pertencer àquela sociedade (de onde se nasce). Origem: é sempre necessária que se tenha uma origem histórica de onde nasce, para que a importância do local de natalidade tenha algum poder simbólico.
} 
os luso-descendentes, os afro-angolanos e os Euro-angolanos sejam submetidos as culturas dos locais onde nascem ${ }^{27}$. Importa salientar que UPA desenvolveu um modelo diferente da UNITA, e tentaremos expor cada particularidade.

\section{(a) UPA/FNLA}

A UPNA parece-nos ter sido apologista a monarquia kongo ${ }^{28}$. Ainda que Holden Roberto tenha optado por um modelo republicano, a presença de substratos kôngo é notória na definição ideológica da UPA. Assim o luso-tropicalismo pareceu a essa organização politica como "manobra" do colonialismo português. O apoio americano, ainda que fosse à logística, determinava a postura negativa da UPA/FNLA (Stokwell, 1979: 86-87, 206, 245)29 perante lusotropicalismo. Alias, Gerald Bender - já em 1962 - desmistificava-o como instrumento neocolonizador. A kôngolidade (Pelissier, 1979: 126) e as influências da zairianização na elite dessa angolanidade (Brinkman, 2003: 5, 7), como serio entrave, desqualificavam a pretensão lusotropicalista. O conservadorismo da UPA - na sua incorporação na modernidade/abertura parecia um neopatrimonialismo moderno (Eisenstatd, 1972), guardando ainda a hegemonia de linhagem reinante. Na base das constatações na Guine Bissau (Forrest, 2003), pode se compreender as fragilidades internas dessa organização face aos condicionantes republicanos/democráticos e, no caso especifico de Angola, a luz dum capitalismo de diamante/petróleo (Hodges, 2001).

A região onde nasceu UPA/FNLA tem características peculiares que não permitiram a implantação efectiva do luso-tropicalismo30. A resistência kôngo perante a implantação portuguesa. Com Luanda já conquistada, o reino do Kôngo deixava de interessar os Portugueses (cansados com as guerras de resistência) que expandiram sua autoridade através do resto de Angola. Tendo o apoio dos E.U.A. (Stockwell, 1979), o luso-tropicalismo era logo desmascarado.

Das quatro constituições hierárquicas da UPA/FNLA (1959-2006) ${ }^{31}$, importa salientar esse quadro significativo:

(1) 68,14\%: Salvador/aristocratas;

(2) 21,06\%: Bazômbo comerciantes;

(3) $3 \%$ : Umbundu

(4) 2,8\%: Ambundu

(5) 2,33\%: afro-descendentes/luso-descendentes

\footnotetext{
27 Benot, 1981; Birnbaum, 1997 ; Nganga, 2008; Andrade, 1997; Neto, 1997; Sinda, 1972

${ }_{28}$ Matumona escrevia: “...do ntotelismo, [UPA] evolui rapidamente para as concepções mais liberais, mais republicanas” (Casmiro, 2011:29).

${ }_{29}$ Estima-se em mais de 80 milhões em 1975, no Consulado do presidente Gerald R. Ford; cerca de 19 milhões foram destinados a UPA/FNLA. Nas contas directas apresentados por John Stockwell, chega-se a 34 milhões, (a dividir entre UPA/FNLA e UNITA).

3o Discurso sur le Colonialisme de Aime Cesaire; Peau noire, Masque blanc, de Franz Fanon; Autobiography de Kwame Nkrumah.

${ }^{31}$ Começa-se na fundação da UPA, a da FNLA, do GRAE, do GURN ate a morte do líder Holden Roberto. Dai para cá, há muitas dissidências que não nos facilita, ainda, estruturar comodamente.
} 


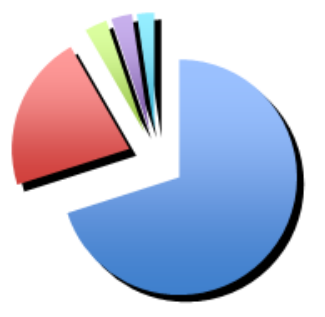

\author{
- Sao Salvador \\ - Bazombo \\ - Umbundu \\ - Ambundu \\ Afro/Luso descendente
}

A resistência kôngo continuou até século $\mathrm{XX}$, de modo que cultivou-se relações de amizade com Portugal: Ngwizako, Nto-Bako são os partidos que defendem a continuação da monarquia kôngo, com relação de amizade (e não de colonização) com Portugal (Pelissier; Wheeler, 2010: 139), não obstante a existência de alguns tratados com os Lûnda, ou o de Simulambuku (Madureira, 2001) por exemplo.

É nesse âmbito que surge a UPNA em Matadi, feita UPA mais tarde. Em Matadi/local natalício, a língua e a cultura francesa são influentes e marcaram os fundadores, e determina a cultura funcional da filosofia política da UPA. E, visto a presença da BMS na região, a influência inglesa era visível (Grenfell, 1998; Lawrence, 2001). Directa ou indirectamente a "civilização portuguesa/católica” contrastava a "civilização francesa laica/inglesa protestante". Dessa lógica, o luso-tropicalismo foi minimizado não só pela postura da negritude ${ }^{2}$, mas também pelo pragmatismo inglês assumido pelos lideres Gana que vão inspirar os líderes da UPA.

Angolanidade rizomática que a UPA optou logo no início vem da UPNA, onde a essência kôngo vigorou: angolano/kôngo sendo aquele que tem linhagem, possuidor das terras ("roubadas"33 pela colonização) constituía o "Eu"; o "Outro" categoriza-se em angolano/naokôngo, também possuidor das terras (mas sem linhagem kôngo) e o "Não-Eu” eram os afroangolanos e os luso-descendentes. Na lista da fundação da FNLA os constituintes respondem a essa estrutura.

A angolanidade rizomatica/UPA parte duma predefinição: sendo o Kôngo um reino amigo de Portugal, o resto dos angolanos/colonizados ocuparia uma posição secundaria. Dai que os militantes kôngo da UPA buscaram impor certa superioridade ao resto dos Angolanos, principalmente Ambundu e Umbundu. Ambundu eram erradamente considerados como “descendentes dos antigos escravizados kôngo" e os Umbûndu, além de escravizáveis, eram tidos como "mão-de-obra” constante quer para os Ambûndu quer para os Kôngo. Por isso, o "Eu” rizomatico/UPA é exclusivamente de origem kôngo. Mas esse “Eu” rizomatico/UPA está subdividido em: (a) aristocrata: os oriundos de Mbânz’a Kôngo/conterrâneos do líder Holden Roberto; (b) comerciantes: oriundos de Zombo/conterrâneos de Emanuel Kunzika; (c)

\footnotetext{
${ }^{32}$ A mesma leitura será feita por Mário Pinto de Andrade na Présence Africaine em Paris. Talvez seja na base da mesma negritude que Mário Pinto e outros, Matias Migueis, Viriato da Cruz, etc. já não se identificarão com angolanidade apriorística pós-independência (Messiant, 2009-II: 146-151).

33 UPA/FNLA tinha um slogan claro: "Liberdade e Terra".
} 
camponeses: oriundos de outras localidades. Os primeiros tinham direito de reinar, os segundos ocupavam posições secundárias e os últimos eram o suporte sociocultural da estrutura existente. Parecem sequelas de longa data (Andrade; Ollivier, 1974:22-24, 27).

O conceito que "Eu" rizomático/UPA tem sobre o "Outro" rizomático/UPA parte de dois suportes: (i) preferencial, por ser "autóctones" 34 os possuidores das terras ancestrais por libertar; (ii) auxiliador a liderança do "Eu" rizomático/UPA por duas razões: "Eu" é suposto ser inteligente/civilizado ao pé de igualdade com o português/civilizado; o estatuto da humilhação do "Outro/rizomático" Interior/não assimilado poderia ser ultrapassado numa colusão estratégica com "Eu".35

O "Não-Eu" rizomático é mais complexo ainda. A ideia geral que se faz sobre ele é que ele ("Não-Eu" risomático) seja todo Euro-angolano e Afro-angolano porque nasceu em Angola ou por um dos seus progenitores ser angolano de categoria "Eu" ou "Outro". Ora, nota-se uma subdivisão entre eles: (i) os Euro-angolanos/Afro-angolanos com filiação com "Eu" não são necessariamente "Não-Eu" risomático/UPA. Os descendentes das alianças matrimoniais com "Eu/Mbanz’a Kongo" são categorizados em "Eu" auxiliar; os descendentes dos matrimónios com "Eu/Zombo" são "Eu" passivo; os descendentes com "Eu/camponês" são, também, "Eu” passivo. A diferença é que "Eu" auxiliar ainda é aristocrata, enquanto "Eu" passivo/zombo ou camponês é reserva36; (ii) descendentes de "Outro" com "Não-Eu" não parecem ser fixamente categorizados mas das leituras sociais que se pode fazer, nota-se que geralmente são ora "Outro" secundário ora "Outro" auxiliar. Secundário por não ser interlocutor confiável ou privilegiado, e auxiliar por servir apenas em alguns fins específicos sem poder de decisão. De modo geral, depende sempre do progenitor: se for masculino, isso dependerá do reconhecimento do filho, que será sem "família" porque quer "Eu" quer "Outro" são matrilineares. Caso for o progenitor feminino, existiam duas linhas de pensamento: na primeira todos tios maternos enquadrariam o sobrinho e a aceitação do "Eu" dependerá da categoria dos tios maternos (aristocratas, comerciantes, camponês); a segunda é que dependia sempre do pai Euro ou Afro-angolano reconhecer o filho (Messiant, 2009-II; 66-67). A teoria de Chabal sobre identidade/localidade (Chabal, 2009: 27-42) parece-nos funcional aqui: o lugar rural/urbano, um acesso a "civilização", definia a categorização de "Não Eu".

Importa salientar, finalmente, o "Não Eu" puro porque é "não-angolano" nascido em Angola. A lei colonial declarava-o angolano (português/angolano) por jus solis. Existiam duas vertentes rizomáticas a volta disso: (i) nascer em Angola não implicava, para as populações patrimoniais, a aquisição da nacionalidade/cidadania [local] angolana. Para ser angolano rizomático/UPA, era necessário observar dois factores: não ser descendentes das famílias escravizáveis ou escravizadas; e ter uma linhagem, isto é, possuir terras dos ancestrais; (ii)

34 Utilizamos esse adjectivo tal como eles próprios preferem.

35 Pode se compreender com a morte de João Batista Traves Pereira que, Segundo Marcos Kassanga, será assassinado por não saber falar kikongo (ANTT, PIDE, Delegação de Angola, p.i, 11.16, fl. 481).

${ }_{36}$ Muitos destes aderiram a MPLA por não encontrar espaço na FNLA, depois da independência de Angola. 
Franz Fanon e Aimé Cesaire influenciaram consideravelmente a negritude da UPA: "Peau noire, masque blanc" e "Discours sur le colonialisme" denunciam a existência do neo-colonialismo a partir das sequelas (da colonização) inelutáveis a condição do Africano, de maneira que os Euroangolanos não poderiam nutrir em "Eu" rizomático alguma confiança/esperança na luta vitoriosa contra a colonização (e seu vício colonialismo). Alias, foi por isso que as famílias "Eu" que providenciavam euro-descendentes eram mal vistas a ponto de perder seu prestígio, o que era relativamente diferente aos "Outro". 37

Depois de se criar a FNLA, alguns anos depois, a sua estrutura (Eu, Não-Eu e Outro) não tinha mudado, de facto. As possíveis negociações entre GRAE e MPLA não esperançavam tanto. Com o governo saído dos Acordos de Alvor, as primeiras dinâmicas tornam-se visíveis, sem portanto que sejam operacionalizadas mudanças significativas: (i) as subdivisões do "NãoEu" deixam de ser discriminatórias internamente, mas continuavam as mesmas na sua generalidade (Giddens, 1984); “o tribalismo/regionalismo" que sistematizava a operação directa entre "Eu" e "Outro" conhecerá rupturas comprometedoras (dissociações de Jonas Savimbi e outros Umbûndu; exoneração de Emanuel Kunzika e outros Bazômbo/Mbûndu; desistência de Marcos Kassanga, e seus aliados militares da ENLA). É aí que nasceu uma outra angolanidade rizomática/UNITA por um lado. Por outro lado, a angolanidade apriorística será vista como melhor abrigo por vários "Eu/comerciantes/camponês" (e suas descendências) e por inúmeros "Não Eu" euro-angolanos/luso-descendentes (e suas descendências), no caso de Beli Belo, por exemplo. FNLA/UPA foi acusado de nutrir a hegemonia kôngo e regionalismo sistemático.

\section{(b) UNITA.}

Há considerações preliminares por fazer aqui: em 1961 os Umbûndu que trabalhavam nas vivendas dos portugueses instalados no Norte não participaram nas atrocidades de 15 de Março (por manter-se fiel ao patrono colono), e muitos pagaram com a vida. O "Outro" da angolanidade rizomática/UPA conhecera uma ruptura epistemológica com o "Eu/UPA". Os Umbûndu injustiçados na Frente de Leste pela angolanidade apriorística/MPLA seguiram o mesmo caminho: (i) as prévias relações de cordialidade/cooperação tornaram-se relações de inimizade/conflitualidade; (ii) as dinâmicas históricas e sociológicas providenciarão "amargura" dos Umbûndu em relação as duas angolanidades e seus suportes institucionais (MPLA e FNLA): se por um lado os reinos umbûndu foram criados pelo poderoso kamundôngo (Coelho, 2009) Katyavala Mbwîla proporcionando intercâmbios onde o Norte pretende dominar o Sul, por outro, a supremacia de Norte (fundador) é ora protestada internamente (entre os Umbûndu), ora é manifestamente posta em causa/duvida quer pelo auto-estima umbûndu quer pela novas dinâmicas socioeconómicas (Muekalia, 2010: 187-186); (iii) a necessidade de uma força

37 Mestiços eram bem-vindos entre os Ambûndu e entre os Umbûndu, com esta classificação: Umbûndu/assimilado ou Ambûndu/assimilado = filhos reconhecidos; Umbûndu/não assimilado ou Ambûndu/não assimilado = filhos não reconhecidos. 
sociopolítica oriunda do Sul interessava os superpoderosos (E.U.A e U.R.S.S.) nas suas expedições geoestratégicas em relação a África Central/Ocidental, e a popularidade dos Umbûndu parecia-lhes muito significante para suas estratégias em toda África meridional 38 .

Essas observações acima mencionadas estão na forja da angolanidade rizomática da UNITA, expressivamente diferente. Preferimos chama-la de angolanitude por refutar (como a negritude) a sua inferioridade (em relação ao "Eu rizomático/UPA" e "Eu apriorístico/MPLA") e negar toda sua submissão das outras angolanidades. Dai que Jonas Savimbi sublinhara uma "luta interna a partir de dentro", como forma nocional da sua angolanitude (Savimbi, 1979). Era uma questão fundamental de não perder a sua ancestralidade num mundo tão moderno (Neto, 1997b); construir a "identidade cultural nacional" na base da realidade sociológica angolana onde interviriam os traços culturais umbundu.

Passamos a estrutura da angolanitude/UNITA:

1) "Eu": Umbûndu

2) "Outro": Autóctone angolano39

3) "Não-Eu": Todo angolanizado.

Umbundu é o "Eu"40 mas importa salientar que está subdividido em: "Eu/monarca", "Eu/nobre" e "Eu/servidor"41. O "Eu/monarca" deve nascer em alguns sítios simbólicos nos costumes umbûndu e pertencer a determinadas linhagens. 42

O resto de Angolano é o "Outro" que se define da seguinte forma: (i) pertencentes aos antigos reinos parametrizados no território angolano, com ligeira preferência àqueles reinos afiliados a Mbayi Lundu, e outros núcleos simbólicos dos Umbûndu (Fabian, 1998: 63; Eisenstatd, 1972: 19, 48; Eriksen, 1992: 39); (ii) os descendentes angolanos de matrimónios com os "Não-Eu” facultam a naturalização dos seus progenitores não-angolanos até certo ponto: não podem assumir altas responsabilidades, e só podem servir; podem assumir algumas responsabilidades secundarias/auxiliares, mas jamais deter o poder de decisão.

"Não-Eu" pode, filosoficamente, ser considerado como o "Nada" de Sartre.43 Parece-nos que seria desta forma que se construiu a estrutura ontológica da angolanitude. Essa

\footnotetext{
${ }^{38}$ Caminho de Ferro de Benguela juntava dois oceanos e interessa os dois super-poderosos.

39 Aqui, angolanitude inspira-se na versão de Hegel (retomado por Sartre): "O ser Para-si só é Para-si através do Outro". Dai o "Nada” ("Não-Eu”), nesse caso, não existe, não serve para nada.

40 "Ser-em-situação" (Sartre, 1973: 637).

${ }^{41}$ Samuel Chiwale menciona nas suas memórias que existem nomes de família que explicam as funções que desempenhavam nos tempos idos (do reino Umbûndu): músico, dançarino, tocadores de batuque, servidor do vinho, guardião da lança do rei, soldados, etc.

$4^{2}$ Jonas Savimbi (Molo Wini) conhecia provavelmente as suas origens principescas ao identificar-se como "Rei dos Mbângala" (Molo Wini = filho do povo/multidão).

43 Traduzimos aqui o "Néant" por "Nada". "Ser-atrás-de-aparição" reflecte ao "Não-eu" que, para integrar-se na Angola, buscou "ilusões ultra-mundo" (luso-tropicalismo, por exemplo). Ser, seria o "Eu”, e o Nada" seria aqui "Eu(-1)" ou ainda "Não-Eu", caso interpretássemos bem os conceitos (Sartre, 1973: 12).
} 
angolanitude/UNITA pretende romper com as angolanidades, 44 e traz a ideia da existência sociocultural como percepção real da nação/Estado angolana. Assim sendo, apenas "Eu" e "Outro" predominem os suportes existenciais (Appiah, 2010: 67, 68;), ao passo que "Não-Eu" (O "Nada") que é apenas referenciado45, e por conseguinte é geralmente ausente no relacionamento directo entre "Eu" e "Outro" 46.

Em relação às primeiras militâncias, nota-se o seguinte quadro:

1) 93,3\%: Umbundu Interior;

2) 2,62\%: Angolano do Centro-Norte/Norte;

3) $2,33 \%$ : Angolanizado africano 47

4) 1,73\%: Litoral/Ango-descendente.

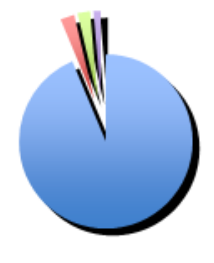

$$
\begin{aligned}
& \text { Umbundu } \\
& \text { - Angolano }
\end{aligned}
$$

Essa estrutura pode, em grande parte, se justificar pela forma como a UNITA surge (primeiro como Associação dos Amigos de Angola) e pelas tensões existentes entre 1964 e 1968: a especificidade da região (Heywood, 1989: 49, 52; Marcum, 1978; Neto, 1997b) pareceu estar, nesse período de ebulição (das lutas de libertação), em silêncio. MPLA que estava na sua vizinhança (Zâmbia) não encontrará grande simpatia das populações locais em relação a UNITA (Chiwale, 2008; Guerra, 2002). A sua angolanidade apriorística não parece ser endogenamente compreendida (Pelissier, 1997), de maneira que até hoje seus adversários da UNITA acusam esta de ter tendências tribalistas. 48

A essência da personalidade cultural - isto é, o sentido de objecto cultural manifestado pelo sujeito autóctone - seria a proto-historia do "Eu” (individuo). Este "Eu” já é estacionário, diferentes de cogito dinâmico de Descartes, de maneira que abnega as transformações das suas culturas internas (mostra-se anti-futurista), a fim de: (i) defender as terras territorializadas pelo "Não-Eu" ao benefício do "Eu"; (ii) revalorizar o seu "passado negado" num universo promotor das transformações49 (Saint-Moulin, s/d: 2, 6).

\footnotetext{
${ }^{44}$ Da mesma forma que "L’Etre et le Néant" rompeu com o tradicional pensar francês nos anos 40-50 do século XX.

45 Jean Paulo Sartre dizia: "Quando penso no meu amigo Pedro, este deixa de existir realmente. Ele passa a ser passivo" (Sartre, 1940[1973]).

${ }^{46}$ Não é necessária a presença de "Ele" quando "Eu" e "Outro/Tu" estiverem a conversar. Logo o "Ele" que é assimilado ao "Não-Eu", pode ser presente/ausente nas realizações.

47 Os angolanos de origem africana: aquele cuja origem está misturada com proveniências duvidosas.

${ }^{48}$ Jonas Savimbi esclarece-nos quando, repetidamente e em varias ocasiões, dizia: "Primeiro é o angolano; segundo é angolano; terceiro é angolano... depois vêm os outros... que deviam ficar nos seus países" (DVD sobre Savimbi, Muata da Paz). Para uma Angola pluri-racial, plurilinguística... é compreensível que tal discurso seja conotado (por algum motivo) separatista/tribalista.

49 As vozes das etnias abafam o projecto da nação.
} 
Somos de opinião que as fragilidades internas foram atenuadas pelo militarismo de Jonas Savimbi, pois não caberia apenas a uma simples retórica da angolanitude. Depois da sua morte, a eleição de Isaías Ngola Samakuva obedecia a umbundidade angolanitunista: sendo de Viyé (Bié) como Jonas Savimbi5o, ele pertence a família dos guerreiros oriundos de Kunje. A sua preferência em relação ao Eduardo Jonatão Chinguji (outro Umbûndu de Bié) justifica-se pelo facto de que, "os Chinguji, sendo da descendência de Chinguri/Chinguji, são [considerados como] verdadeiros detentores da superioridade do Conselho dos Velhos no antigo reino de Mbayi Lundu/Huambo". ${ }^{11}$ Explicar-se-ia, com esse depoimento, porque os Chinguji foram sistematicamente assassinados sob ordem de Jonas Savimbi. Em relação ao Armindo Lucas Paulo Lukamba "Gato" (outro Umbûndu do Huambo), ele não poderia reinar porque era do Huambo: acredita-se que os legítimos por reinar (como os antigos monarcas) vêm de Norte/Bié. Talvez seja por isso que Abel Epalanga Chivukuvuku, depois de se ver afastado, terá criado um partido a parte. Mas será que a estrutura do “Eu/angolanitude” perderá consistência?

Abel Epalanga Chivukuvuku é internamente aceite como líder pela mesma leitura de "Eu/angolanitude", e dois aspectos sustentam-no: (i) local/originalidade de onde ele nasce: Luvêmba, em Mbayi Lundu (Huambo), era o local mítico onde antigamente eram investidos os monarcas. Também o seu pai, Sanjando Chivukuvuku tinha filiação com a linhagem dos sacerdotes/chefes da terra, e a sua mãe (Margarida Chilômbo) da linhagem com afinidade guerreira52. Isto é, o seu local/origem o legitima como líder das massas; (ii) o percurso político que conheceu: da Inteligência Militar da UNITA ao conselheiro de Jonas Savimbi valeu-lhe um mérito no seio da UNITA. Há leituras segundo as quais a sua passagem em Luanda 1993-1994 permitiu-lhe ganhar possíveis alianças com MPLA (o que muito apontam na publicitação do seu partido recém-formado: CASA-CE/Março 2012) e as suas experiências diplomáticas o teria assegurado financeiramente.

\section{Angolanidade aposterioristica}

As euforias patrióticas se confundem entre as "culturas locais" e a "cultura global" na defesa dos valores identitárias (Boas, 1945[1917]: 156), de maneira que por um lado, as angolanidades passam ser "coisa passada/mas ainda útil”, e por outro, a expressividade dos noventistas aglutina dois aspectos: (i) reforma da libertação independentista na Era da democratização do mundo; (ii) ruptura promovida por outras forças políticas ao detrimento do mono-partidarismo. Pois, inicia-se aqui a redefinição infindável das duas angolanidades e angolanitude.

\footnotetext{
$5^{\circ}$ Molo Wini era o Rei dos Mbêngala/Jagas.

${ }^{51}$ Depoimento de Pedro Kaluvungu.

${ }^{52}$ Umbûndu sendo uma população geralmente considerada guerreira pelos etnólogos e etnógrafos, justificaria a popularidade de um descendente uterino da linhagem guerreira.
} 
As transformações sociais que os noventistas vêm impor em Angola definem essa angolanidade. Mas para compreender melhor devemos ter em conta a forma como o mundo estaria aqui a ser democratizado - depois da queda da U.R.S.S/murro de Berlim - e, sobretudo, da forma como os próprios angolanos efectivam a democracia no seu país. Agora, porque apriorística?

Essa angolanidade não é original no seu nascimento e desenvolver-se-á sem originalidade interna. Ela é consequencial ( a priori), logo nela encontramos varias causas, uma complexidade definicional e, sobretudo, uma transformação contínua. Dos traços identitários definidores, essa angolanidade tem uma origem plural: (1) efeitos da democratização/globalização "angolanamente" vividos; (2) as insatisfações dos independentistas na pós-independência; (3) integração económica e busca de justiça social pretendem romper o statuquo sequenciado pelo nacionalismo administrativo/económico (Pimenta, 2008). Trata-se da angolanidade economicus.

A estrutura dessa angolanidade ainda pode parecer complexa por estar ainda em ebulição. Quem é o "Eu"? Quem seria o "Não-Eu" e, a quem encontramos características de "Outro"? Se reparamos bem, cada angolanidade responde a uma linha peculiar na categorização desses constituintes, o seu cruzamento aqui devera responder a uma teoria coerente (partindo das angolanidade/teorias estruturantes diferentes).

No período que surge essa angolanidade, o capitalismo torna-se condicionado pelas dinâmicas do petróleo (e produtos derivados) e diamante53. Razão pela qual essa angolanidade parece-nos mais económica e, por conseguinte, neo-capitalista.

1) "Eu": economicamente assumido pelo "Eu/apriorístico"; territorialmente o "Eu/rizomático", "Eu/angolanitude" e "Eu/apriorístico" estão em contínuo duelo.54 Esse duelo parece dinamizar e integrar as diferentes angolanidades;

2) "Outro: economicamente, temos "Eu/rizomático" e "Eu/angolanitude"; na perspectiva do território, parece parcialmente ser "Eu/apriorístico"/luso-descendente e afroangolano.

3) "Não-Eu" passaria a ser "Eu/rizomático" rural, "Eu/angolanitude" rural e "Eu/apriorístico" rural e periférico.

Como podemos notar, o cruzamento de cada agente nessas diferentes angolanidades não parece estabelecer seu espaço comum onde, confortavelmente, as suas estruturações possam servir em teorias existentes (Nadel, 1962; Giddens, 1984; 1994; Malinowski, 1944):

\footnotetext{
53 Jonas Savimbi sustentou a sua guerrilha com diamante. Rafael Marques Morais publicou um relatório interessante acusando governantes e altas patentes das FAA enriquecerem-se com "diamante de sangue".

54 Trata-se de uma questão psicológica e social ao mesmo tempo. A identificação de cada constituinte implica, por conseguinte, uma tendência hegemónica: idealização identitária.
} 
(1) Pseudo-intercâmbio dos "Eu": a politização desse discurso faz com que a estruturação nos seja inviável; apesar do elemento "finanças" esteja a promover o "Eu” apriorístico, a sua hegemonia é ainda instável perante o "Eu" rizomatico e "Eu" da angolanitude por outras razões;

(2) Incompatibilidade de "Outro": as funções dos "a priori ontológicos" confundem-se entre "Outro" e "Não-Eu", por um lado. Por outro, as realidades definidoras das dinâmicas relacionais são incompatíveis, e o seu percurso histórico é intermitentemente conflitual.

(3) Distanciamento das partes em "Não-Eu": a dialéctica entre os "a priori ontológicos" contribui mais para afastamento de um de outro, pelas suas naturezas estruturais conflituosas; o diálogo é uma pausa musical, quase nulo nos momentos/espaços que envolvem centros de habitus definidor de "Não-Eu” comum.

Quer com isso dizer que as tendências locais da cultura/angolanidade ainda vigoram ao detrimento da acepção global: angolano ainda é local (ver os dados estatísticas anteriores), e é apenas por causa da desigualdade perante todos suportes simbólicos que os identificam como nação angolana que se quer criar55 (Milano, 2005).

Contudo, a ideia que essa estruturação leva é que, o "centro" providencia a hegemonia económica, cultural e social. As relações entre os agentes proporcionam outros habitus (Bordieu) que, fundamentalmente, determinam um novo jogo que vai se compondo nas bases históricas (Nadel, 1962). Tudo indica que essa disposição partiria de um jogo das práticas póscoloniais (Coquery-Vidrocitch, 1985), e ainda não fundamentalmente a partir de uma estrutura prescritiva/prévia (Auge; Colleyn, 2010:104). As outras angolanidades já apresentam certa estrutura que explicaria, pelo menos teoricamente, o comportamento psicossocial dos seus constituintes. Já com angolanidade aposterioristica, interessa-nos compreender os "a priori" ontológicos ("Eu", "Não-Eu” e "Outro") nas suas oposições representativas e práticas (Geertz, $1988,34)^{56}$. Eles promovem ou/e são promovidos por jogos tidos como lutas políticas (Reis, 2003:134; Bordieu, 1989: 17; Bordieu, 1991: 117) na base de vários agentes culturais que dinamizam seus traços identitários (Khan, 1996: 37).

As quatro principais diferenças entre essas angolanidades são: (i) rizomática e angolanitude centralizam-se no indivíduo patrimonialista; enquanto a apriorística considera as dinâmicas socioculturais e socioeconómicas como provedor do "lugar comum"; aposterioristica é globalizadora e suas metamorfoses são consequenciais dos repertórios económicos; (ii) rizomática estaciona-se no tempo (Levi-Strauss, 2008); angolanitude reconstrói o seu paraíso cultural ancestral (Eliade, 1969); apriorística busca nas dinâmicas históricas a sua estrutura social urbana e urbanizadora sempre futurista (Cohen, 1969); aposterioristica é onde o capital

55 Aconselhamos os artigos em: Adibe, 2008; Delamoi; Taguieff, 1991; Chatterjee, 1993.

${ }_{56}^{6}$ Anthropological praxis, na linguagem de Clifford Geertz. 
sociocultural emana da razão estética (Balandier, 1980); (iii) a categorização dos constituintes é incompatível e conflituosa, o que torna seu intercâmbio desconfortável na forja do modelo para a construção da nação (Marcum, 1978: 103-106), por um lado. Por outro, as suas perspectivas serão influenciadas pelos seus patrocinadores estratégicos, ora estes são adversários; (iv) a segmentação da futura nação (Chaterjee, 1993: 68) parte aqui dos alicerces das premissas fragmentadas, quer pela etnicidade passiva que predominou nas organizações independentistas e as suas implicações socioculturais actuais, quer pela postura activa que os novos tempos irão impor às novas propostas políticas e realidades socioeconómicas (Mollander, 2009; NtoniNzinga, 1999).

Nota-se que a estruturação ("Eu", "Não-Eu” e "Outro") de cada angolanidade depende ora das influências externas (Foucault, 1987), ora parte das dinâmicas internas (Giddens, 1994).57 Ora, os seus espaços sociais [e os seus tempos sociais] categorizam capitais (recursos, bens e práticas sociais) que se apresentam sob varias configurações, concomitantes de valores desiguais e a repartição permanecerá desigual, também. Os seus "a priori ontológicos" que se assimilam as "identidades colectivas" apresentam - culturalmente - grande abertura do seu intercâmbio, talvez porque assim exige a modernidade, de modo que apenas a questão económica será sobrevalorizada entre os todos os capitais (Bordieu).

Como podemos o notar, a angolanidade aposterioristica apresenta motivos de um discurso na dimensão do Estado, e por conseguinte, a mais actualizada na discussão do projecto da nação angolana. Ainda assim, as suas idiossincrasias são pouco consistentes. Contudo, são importantes na dimensão de Estado (Locke, 2006:11), os relacionamentos existentes entre as duas angolanidades e a angolanitude quer no princípio de reciprocidade, quer na aliança e filiações entre elas (Levi-Strauss, 1977) quer no conflito que, em alguns momentos, se verifica internamente. A partir desses relacionamentos, pode se estabelecer o quadro provisório da nação que o Estado angolano poderá criar no seu novo discurso de angolanidade aposterioristica.

Levi-Strauss explica que a forma primitiva de "troca" não tem apenas nem essencialmente um carácter económico. A sua significação é, simultaneamente, social e religiosa, mágica e económica, utilitária e sentimental, jurídica e moral (Levi-Strauss, 1977:61).

$\mathrm{Na}$ angolanidade apriorística, a reciprocidade entre "Eu" e "Outro" varie essencialmente em três vertentes: (i) os parentes de cada um (Radchliffe-Brown, 1952:52) relacionam-se indirectamente a ponto de construir periferias protectoras simbólicas do "Eu" na sua aproximação com "Outro"; (ii) os irmãos de ambas partes mantêm relações directas; (iii) os "Não-Eu" são "pontes utilitárias" para "Eu” e "Outro". No ponto (ii) a afinidade/relação

57 Giddens fala de auto-identidade. 
(Dumont, 1971:13-14) gere o "bem-estar"58 social porque constitui o núcleo económico da sociedade aparentemente projectada pelo MPLA/Estado. O ponto (i) busca um suporte moral na sociedade - mas apenas tranquilizador face a justiça social em relação ao "Não-Eu" e seus parentes - embora, em última instância, dá-se conta que sejam porta-voz dos seus "parentes" ("Eu" e "Outro"). Partindo de pressuposto que MPLA forjou-se, geograficamente, num espaço mbundu (Miller, 1995: 43) e Metrópole, e tendo em conta que o seu "Eu" tenha o poder, importa salientar aqui que o sentido de ngundu que determina filiação (que a seu turno orienta os relacionamentos) parece-nos ser uma requalificação de ngundu numa sociedade neo-capitalista, dominada pela nova nomenclatura. Lembramos aqui que este poder é sem instituição (Foucault, 1987), por um lado: o saber, o know-how estratégico ainda pertence ao "Eu" apriorístico por possuir a formação qualificada em ciências estratégicas relacionadas com petróleo, diamante e novas tecnologias. Por outro lado, o poder institucionalizado (Santos, 1994) ainda pertence ao "Eu" apriorístico: nas empresas multimilionárias, nos bancos, nas administrações públicas... são os "Eu" apriorísticos sócios e gestores. Nas duas vertentes, está claro que ainda detém o poder na sua totalidade definicional, e as transformações seriam contínuas, de modo que as rupturas são apenas históricas, mas os problemas continuam os mesmos e as forças de decisão noutras formas.

$\mathrm{Na}$ angolanidade rizomática/UPA, notamos quatro leituras dos relacionamentos entre os constituintes: (i) o "Eu conservador" 59 no seu "local kôngo" encontra conforto directamente com o "Outro conservador" no seu "local angolano" de maneira que os descendentes dessas relações encontram apoio social, simbólica e moral na própria sociedade rural (cuja natureza ainda preserva o seu cultural6o); (ii) as relações são intermitentes entre "Eu" e "Outro" por causa da enorme incompatibilidade entre os traços de ambos e conflitualidade regida pelas suas idiossincrasias comportamentais.

Repara-se que da U.N.I.T.A surgiu C.A.S.A-C.E pela mesma teoria (angolanitude). Chivukuvuku é aceite não só internamente, mas as suas velhas relações diplomáticas valeramlhe uma legitimação impressionante. A História repete-se (dizia Heródoto): tal como o foi Jonas Savimbi em relação a UPA/FNLA, o mesmo parece ter acontecido com Abel Chivukuvuku em relação a U.N.I.T.A. O interessante agora é que no caso de Jonas Savimbi, tratava-se da hegemonia kôngo em relação à um Umbûndu. No caso de Albel Chivukuvuku, assiste, porém, a negação hegemónica duma família em relação ao todo grupo umbûndu.

Como podemos notar, as identidades comunitárias (dos grupos societários) permanecem numa época em que as angolanidades se fundiram (em aposteriorística), num mundo globalizado (e de globalização) onde a nacionalização da identidade dos constituintes

${ }_{58}$ Estamos a referir especificamente a: (i) emprego digno e provedor da estabilidade financeira; (ii) promoção profissional e geradora de rendas dignificadoras; (iii) equilíbrio social nas necessidades basilares humanas.

59 Geralmente diz-se que UPA/FNLA era tradicionalista ("Eu conservador"). O mesmo e dito para a UNITA ("Outro conservador") e mesmo para o MPLA ("Outro conservador").

6o Em Mbânz’a Kongo existe uma arvore secular chamada Yala Nkuwu, união dos. Em Mbâyi Lûndu há montanha sagrada e unificadora, etc. 
não equaciona as suas diferenças. Localmente as identidades são unitárias, regionalmente elas mantêm um inter-câmbio predominado pelas ofertas culturais (fundamentalmente económicas) e nos perímetros de Estado-nação, elas reconstroem-se continuamente.

Angola não nos parece ter culturas fragmentárias proporcionando a etnicidade. Como já vimos sua guerra terá selado socialmente os grupos societários existentes na sua superfície e as novas dinâmicas estabeleceram "lugares comuns" entre eles. As relações de reciprocidade entre essas angolanidades buscam internamente as suas indiferenças a partir das filiações históricas e antropológicas.

$\mathrm{Na}$ forja dessas angolanidades - entre 1960 e 1974 - a vizinhança de Angola setentrional era pró-americana e pró-soviético ${ }^{61}$ ao mesmo tempo. O sul de Angola estava também discutido pela Guerra fria, onde África do Sul e Zâmbia mantinham posturas próamericanas. Essa questão influenciou sobremaneira as características da angolanidade: as afiliações internas das populações patrimoniais angolanas serão influenciadas pelas políticas externas dos países vizinhos, permitindo sub-alianças. Dar-se-á o exemplo dos Kôngo angolanos em fronteira com Congo Kinsâsa (UPA/FNLA) em relação aos Kôngo angolanos em relação aos de Congo Brazzaville (MPLA). Ou ainda, os Lûnda/Côkwe angolanos com a Zâmbia (MPLA/UNITA) em relação aos Lûnda/Côkwe do Congo Kinsâsa (MPLA). Esse quadro será tido em conta endogenamente na construção das identidades regionais, suas aproximações noutras regiões continentais e os subsídios socioculturais que aportam na identidade colectiva angolana.

\section{Últimas palavras...}

Desde finais dos anos 80 do século XX, conhecer-se-ão conquistas democráticas significativas que já mencionamos nas dinâmicas das angolanidades: contudo, essa angolanidade permanece económica por excelência.

\footnotetext{
${ }^{61}$ Entre 1963 e 1970, sublinha-se vários golpes de estado em África, que estabelecem um mapa geoestratégico à mercê da Guerra fria: 13 de Janeiro de 1963: Togo; entre 12 e 15 de Agosto de 1963: Congo/Brazzaville; entre 19 e 28 de Outubro de 1963: Benim; 18 de Fevereiro de 1964: Gabão; 1 de Janeiro de 1965: Republica Centro-Africana; 4 de Janeiro de 1965: Burkina-Faso; 18 de Junho de 1965: Argélia; 25 de Novembro de 1965: Congo/Kinsâsa; 22 de Dezembro de 1965: Benim; 15 de Janeiro de 1966: Nigéria; 24 de Fevereiro de 1966: Gana; 29 de Julho de 1966: Nigéria; 29 de Novembro de 1966: Burundi; 13 de Janeiro de 1967: Togo; 24 de Marco de1967: Serra Leoa; 17 de Dezembro de 1967: Benim; 18 de Abril de 1968: Serra Leoa; 3 de Agosto de 1968: Congo/Brazzaville; 4 de Setembro de 1968: Congo/Brazzaville; 19 de Novembro de 1968: Mali; 25 de Maio de 1969: Sudão; 1 de Setembro de 1969: Líbia; 15-19 de Outubro de 1969: Somália; 10 de Dezembro de 1969: Benim; 30 de Janeiro de 1970: Lesoto (Nkrumah, 1973: 58).
} 